ISSN: 2386-3919 - e-ISSN: 2386-3927

DOI: https://doi.org/10.14201/et2018361223248

\title{
LA CÁMARA DE LAS MARAVILLAS DE MARK RYDEN: FORMACIÓN DEL PROFESORADO DE CIENCIAS SOCIALES EN EDUCACIÓN ESTÉTICA, CULTURA POPULAR Y LITERACIDAD CRÍTICA
}

\section{Mark Ryden's La Cámara de las Maravillas: social studies training teacher using aesthetic education, popular culture and critical literacy}

\author{
Laura TRIVIÑO CABRERA \\ Universidad de Málaga \\ Correo-e: laura.trivino@uma.es
}

Recibido: 2.12.2017; Aceptado: 20.3.2018; Publicado: 30.06.2018

Ref. Bibl. LAURA TRIVIÑO CABRERA. La Cámara de las Maravillas de Mark Ryden: formación del profesorado de Ciencias Sociales en educación estética, cultura popular y literacidad crítica. Enseñanza E Teaching, 36, 1-2018, 223-248.

RESUMEN: El objetivo de este trabajo de investigación es proponer tres retos al profesorado en formación que eliminen tres resistencias desde la literacidad crítica y la didáctica de la sospecha. La resistencia a considerar los espacios artísticos contemporáneos como espacios de enseñanza-aprendizaje. La resistencia a considerar la educación estética necesaria y al mismo nivel que la educación artística. La resistencia a incorporar la cultura mediática y audiovisual al currículum escolar de Historia, Geografía, Arte y Filosofía. Para afrontar dichas resistencias, desarrollamos un diseño de investigación educativa que fomentase competencias críticas, estéticas y audiovisuales en el profesorado en formación, perteneciente al Máster Universitario en Profesorado de Educación Secundaria Obligatoria y Bachillerato, en la especialidad de Ciencias Sociales, de la Universidad de Málaga, a través de la obra del artista Mark Ryden, "padre del surrealismo pop". Para ello, hemos llevado a cabo una implementación en las asignaturas Diseño y desarrollo de programaciones y 
LA CÁMARA DE LAS MARAVILLAS DE MARK RYDEN: FORMACIÓN DEL PROFESORADO DE CIENCIAS SOCIALES EN EDUCACIÓN ESTÉTICA, CULTURA POPULAR Y LITERACIDAD CRÍTICA

actividades formativas y El currículum de Historia, Geografía y Filosofía, que partiera de la visita a la exposición La Cámara de las Maravillas de Mark Ryden (Centro de Arte Contemporáneo de Málaga, 2016). Este trabajo de investigación integra el proyecto de investigación titulado "Literacidad Multimodal y Estudios Culturales: hacia una educación ciudadana en la sociedad postmoderna" que persigue la introducción de la cultura mediática en la formación del profesorado desde la literacidad crítica.

Palabras clave: educación estética; formación del profesorado; cultura mediática; literacidad crítica.

SUMMARY: The goal of this research work is to propose three challenges for the trainee teachers, challenges aimed to eliminate three key resistances to critical literacy and a suspicion-based teaching: The Resistance to consider artistic spaces as learning/teaching spaces, the Resistance to consider aesthetic education to be at the same level as artistic education, and the Resistance to incorporate media and audiovisual culture into the curriculum of History, Geography, Art and Philosophy. To fight these resistances we developed this education research project, whose aim is to promote critical, aesthetic and audiovisual skills in the training teacher for Master's in Teaching Compulsory Secondary Education, Post-Compulsory Secondary, Social Sciences (Art, Geography, History and Philosophy) at the University of Málaga. We used the work of Mark Ryden, "father of pop surrealism». The objective was that students learnt to be suspicious and to acquire critical thinking. To this end, we developed an implementation through Mark Ryden's exhibition La Cámara de las Maravillas at the Centro de Arte Contemporáneo in Málaga. This research work is integrated into the Research Project titled "Multimodal Literacy and Cultural Studies: Towards a citizenship education in postmodern society" that is focused on the introduction of the media culture in training teacher from critical literacy.

Key words: aesthetic education; training teacher; media culture; critical literacy.

\section{INTRODUCCIÓN}

La importancia de abordar la planificación de actividades en espacios museísticos en las asignaturas Diseño y desarrollo de programaciones y actividades formativas y El Currículum de Historia, Geografía, Arte y Filosofía del Máster Universitario en Profesorado de Educación Secundaria Obligatoria y Bachillerato (Especialidad: Ciencias Sociales) de la Universidad de Málaga nos ha llevado a centrar nuestra investigación en el fomento de la educación estética en la formación del profesorado de Ciencias Sociales a través de la visita a la exposición La Cámara de las Maravillas de Mark Ryden en el Centro de Arte Contemporáneo de Málaga (del 16 de diciembre de 2016 al 5 de marzo de 2017).

Rescatando la emblemática locución latina "sapere aude», es decir, "atrévete a saber» manifestada por Inmanuel Kant en su célebre ensayo ¿Qué es la Ilustración? (Was ist Aufklärung?) (1784), hemos desarrollado un diseño de investigación 
LA CÁMARA DE LAS MARAVILLAS DE MARK RYDEN: FORMACIÓN DEL PROFESORADO DE CIENCIAS SOCIALES EN EDUCACIÓN ESTÉTICA, CULTURA POPULAR Y LITERACIDAD CRÍTICA

educativa para la formación del profesorado titulado ¡Atrévete a Sospechar en el País de las Maravillas de Mark Ryden! El concepto "pensar» O "saber» puede también dar paso al "sospechar», esto es, «descubrir qué nos quieren decir en lugar de descubrir qué nos están diciendo» (Ricoeur, 1978, citado en Acaso, 2009: 157). Por tanto, partimos de los principios de la "didáctica de la sospecha" de la profesora María Acaso (2009), entre los cuales se encuentran la necesidad de que el profesorado enseñe a sus estudiantes a sospechar sobre la cultura visual que le rodea y el desmantelamiento del currículum oculto visual. De modo que hemos desarrollado una investigación educativa que promueva la sospecha, que nos sitúe como docentes que tengan el compromiso de enseñar a cuestionarse noticias y demás informaciones emitidas por los medios de comunicación en una época caracterizada por la posverdad; forjar el pensamiento crítico del futuro profesorado.

Y, para ello, ese jatrévete a sospechar! tendrá como eje fundamental, la obra de Mark Ryden. Y, ¿por qué Mark Ryden? Por dos razones fundamentales. En primer lugar, porque estamos ante una exposición de una ciudad como Málaga que llega a superar las 10.800 visitas, récord histórico, no es algo habitual (Europa Press/ CAC Málaga, 2016). La exposición es calificada de la siguiente manera en la web personal del artista: "Mark will have a major restrospective of his work exhibited in Málaga, Spain at the Centro de Arte Contemporáneo de Málaga» (Ryden, 2016). Se trata de una situación que solo puede darse ante un interés desmesurado de la ciudadanía por una obra que le causa curiosidad y asombro; y justamente es lo que define la obra de Mark Ryden, permite que las personas conecten sueño y realidad y esa realidad es cercana a las y los visitantes, la cultura mediática. Y he aquí la segunda razón, porque justamente su obra nos conduce hacia elementos característicos de la hegemonía cultural estadounidense, reconocibles por cualquier persona puesto que forma parte de esa cultura visual de comunicación de masas que nos rodea.

Bajo el título La Cámara de las Maravillas (CAC Málaga, 2016), haciendo un guiño a los espacios dedicados a gabinetes de curiosidades durante los siglos XVI y XVII, que supusieron los antecedentes de los museos, el Centro de Arte Contemporáneo de Málaga acogió una exposición temporal que no dejaría indiferente a nadie. Asimismo, debemos decir que optamos por «ese país de las maravillas de Ryden" porque es importante observar la crítica a la sociedad, un cierto trasfondo del momento que vivimos tras un mundo infantil, al igual que plasmó Lewis Carroll para hacer un análisis de la sociedad victoriana, a través de Alicia en el País de las Maravillas (1865). La muestra transcurrió del 16 de diciembre de 2016 hasta el 3 de marzo de 2017. La exposición albergaba 55 obras, lienzos y esculturas, que comprendían un total de 20 años de trabajos de Ryden y su comisario, Fernando Francés, la definía:

Más cercano al arte comercial y a las nuevas corrientes underground influidas por movimientos musicales como el rock, el deathrock, el heavy metal o el punk, la atracción por lo esotérico y la subcultura gótica, la iconografía cotidiana procedente del cómic, la ilustración y los pósters, la publicidad en una especie de 
LA CÁMARA DE LAS MARAVILLAS DE MARK RYDEN: FORMACIÓN DEL PROFESORADO DE CIENCIAS SOCIALES EN EDUCACIÓN ESTÉTICA, CULTURA POPULAR Y LITERACIDAD CRÍTICA

postmodernidad no oficial, la literatura fantástica, el road movie, la customización de motos y coches, el juguete, las camisetas con simbologías de todo tipo, el uso del sticker, el skate y el grafiti (CAC Málaga, 2016)

Podemos hallar elementos y símbolos de la cultura pop estadounidense (la muñeca Barbie, Santa Claus, cantantes pop como Michael Jackson, Katy Perry...); personajes históricos cruciales para los Estados Unidos como Abraham Lincoln; ambientes de otros tiempos históricos como la Antigüedad Clásica, la Revolución Industrial y la época victoriana; alusiones literarias a las novelas de Charles Dickens y a Lewis Carroll; aspectos religiosos y masonería, etc. De modo que era una colección idónea para conectar conocimientos históricos y artísticos con el currículum escolar desde la cultura mediática.

\section{MARCO TEÓRICO: EDUCACIÓN MUSEÍSTICA, ESTÉTICA FILOSÓFICA Y PATRIMONIO AUDIOVISUAL PARA LA FORMACIÓN DEL PROFESORADO DE CIENCIAS SOCIALES}

Abordar la obra de Ryden como material para el currículum escolar de Historia, Geografía, Filosofía y Arte nos situaba ante tres grandes resistencias que muestra el alumnado del MAEs. La primera de ellas era concebir las actividades fuera del aula como momentos donde no tiene cabida el proceso enseñanza-aprendizaje que estipula el currículum oficial; o, en tal caso, solo pudiera darse en "museos tradicionales», entendiendo por estos célebres pinacotecas, en contraposición a centros de arte o galerías contemporáneas. En segundo lugar, el alumnado del maEs consideraba la aceptación de la educación artística en el currículum oficial versus la irrelevancia de la educación estética en la enseñanza histórico-artística; esto es, se aprende estudiando la información relevante y seleccionada de la Historia del Arte, aquella propuesta por el currículum oficial, frente a las posibilidades de una educación basada en la contemplación estética. En tercer lugar, la cultura audiovisual o mediática no sería adecuada para ser enseñada en las materias de Ciencias Sociales, pese a que vivimos en un mundo donde impera la "contaminación audiovisual", donde convivimos constantemente con espacios audiovisuales a través de las tecnologías digitales y redes sociales o incluso se insertan en el propio paisaje urbano.

Derribar estas tres resistencias constituían los principales objetivos del diseño de investigación educativa. La Estética Ryden permitió que el alumnado pasara de la concepción de un modelo de escuela tradicional basado única y exclusivamente en el currículum oficial a un modelo de escuela innovadora que desvele el currículum oculto a través de la sospecha y desarrolle un currículum postmoderno. 
LA CÁMARA DE LAS MARAVILLAS DE MARK RYDEN: FORMACIÓN DEL PROFESORADO DE CIENCIAS SOCIALES EN EDUCACIÓN ESTÉTICA, CULTURA POPULAR Y LITERACIDAD CRÍTICA

1.1. Con "E» de Educación: sobre los espacios museísticos, la exposición de Mark Ryden y el proceso de enseñanza-aprendizaje

Considerar que el proceso enseñanza-aprendizaje no puede darse fuera del contexto del aula es ubicarse ante un modelo de enseñanza tradicional; contrario a las nuevas metodologías que apuestan por la necesidad de que el alumnado sea consciente de su papel activo en la construcción de su propio conocimiento y de la importancia, para que dicho proceso sea efectivo, de situarse ante otros espacios, como los museísticos, donde les acerquen a la adquisición de otras competencias básicas para la educación ciudadana. Es por ello que hemos articulado tres conceptos en torno a la educación museística.

El primero de ellos es el espacio museístico, concretamente, el Centro de Arte Contemporáneo de Málaga. El objetivo es que podemos ampliar la idea de visita al museo, contemplando las posibilidades de los centros de arte contemporáneos, abierto en muchos casos más a las demandas y movimientos sociales de los entornos urbanos que museos de un largo recorrido histórico y académico. El espacio elegido, el Centro de Arte Contemporáneo de Málaga (CAC), era un lugar de encuentro idóneo para mostrar al alumnado del máster las diferencias entre los museos y los centros de arte; así como las oportunidades que ofrecen, estos últimos, para la educación ciudadana.

A través de la exposición permanente La Cámara de las Maravillas de Mark Ryden, teníamos la oportunidad de deconstruir la percepción del profesorado en formación sobre lo que es una exposición artística. El alumnado del MAEs entendía que las visitas a los museos se ceñían a contemplar lo que se podría considerar como "Alta Cultura"; estando la "baja cultura" totalmente descartada dentro del ámbito escolar por su nulo valor educativo. Recordemos cómo Huyssen hablaba de «la gran división... (un) discurso que insiste en la distinción categórica entre el gran arte y la cultura de masas» (Storey, 2012: 240), entendida también como cultura popular opuesta al arte.

Una cultura para la que Williams comprende cuatro significados: «que gusta a muchas personas", "obra de tipo inferior", "obra que intenta deliberadamente ganarse el favor de la gente», "cultura hecha por la gente para ellos mismos» (Storey, 2012: 19). Para el profesorado en formación, la obra de Ryden representa la cultura popular; pudiendo ser entendida, según Bourdieu, como

cultura comercial, producida en masa, mientras que la alta cultura es el resultado de un acto individual de creación. [que] merece una respuesta moral y estética, mientras que la primera sólo precisa una ligera inspección sociológica para desvelar lo poco que pueda ofrecer (Storey, 2012: 21).

Así pues, esta era otra de nuestras intenciones, deconstruir ese pensamiento que alejaba la cultura visual del currículum escolar; llegando, así, hasta la idea de que el proceso enseñanza-aprendizaje es posible en los espacios museísticos, concretamente a través de los centros de arte contemporáneo y a través de una 
LA CÁMARA DE LAS MARAVILLAS DE MARK RYDEN: FORMACIÓN DEL PROFESORADO DE CIENCIAS SOCIALES EN EDUCACIÓN ESTÉTICA, CULTURA POPULAR Y LITERACIDAD CRÍTICA

exposición como la de Ryden. En este sentido, nos decantamos por la línea seguida por McRobbie, quien manifiesta cómo los Estudios Culturales deben tener presente la investigación sobre el consumo, en su dimensión placentera y creadora de significado (citada en Storey, 2012: 306).

Pero todo ello no debía olvidar que forma parte de un proceso. La educación museística no abarca únicamente el espacio museístico. Cualquier visita museística contempla tres fases: una fase previa de ideas previas en el aula, una fase in situ en el espacio museístico y una fase final de reflexión sobre la exposición.

\subsubsection{Objetivo con «E» de educación}

Aproximar al profesorado en formación al conocimiento y al estudio de la obra de Mark Ryden.

\subsection{Con "F» de Estética Filosófica: sobre la formación del profesorado, el feminismo y Funch y las funciones estéticas de Leontiev}

La aproximación hacia la obra de arte en un museo también se contempla de forma tradicional. Para el profesorado en formación, la contemplación del arte en los espacios museísticos consiste en que la o el guía explique, ante la obra y ante el alumnado, todos los datos que rodean dicha obra. No se trata de interpretar, sino de informar; no se trata de sentir, sino de reconocer elementos técnicos. Para el alumnado del MAEs, un Picasso, un Rembrandt, un Miguel Ángel... informan de corrientes y de hechos relevantes dentro de esa Historia del Arte en mayúsculas; pero quedan cerrados a la pregunta sobre qué emociones proyectan en las/os espectadoras/es y qué interpretaciones se derivan de estos por parte del público. Esto no era de extrañar si teníamos en cuenta cómo se enseñaba la asignatura Historia del Arte en segundo de bachillerato; eliminando cualquier indicio de experiencia estética y sentimientos particulares causados por la propia obra en los comentarios artísticos.

En las materias escolares, aparte del arte, se considera que es mejor dejar la emoción fuera del aula, allí donde la cognición, sin lazos con la emoción, se supone que toma el relevo. Sin embargo, el aprendizaje tiene lugar basándose en conexiones cognitivas, incluidas aquellas que tienen que ver con la emoción, y más conexiones quiere decir más aprendizaje. El aprendizaje depende del compromiso del alumno, que es un indicador de inversión emocional (Freedman, 2006: 98).

Al hilo de este panorama, merece mencionar a Dewey, quien concibe que la educación no puede ir separada de la experiencia estética, la cual proporciona emoción e imaginación. De manera que era esencial que en las aulas quedaran contempladas tanto la educación artística como la educación estética (Freedman, 2006: 68-70). 
LA CÁMARA DE LAS MARAVILLAS DE MARK RYDEN: FORMACIÓN DEL PROFESORADO DE CIENCIAS SOCIALES EN EDUCACIÓN ESTÉTICA, CULTURA POPULAR Y LITERACIDAD CRÍTICA

Esto nos lleva a plantear que el profesorado observa las obras artísticas como contenedores de conocimientos sobre nuestro mundo. La obra y la autoría desempeñan el papel de "emisor educativo-activo»; el alumnado es el "receptor educativo-pasivo". Esto lleva a que estamos ante la negación de una recepción educativa-activa del alumnado, en la que intervengan sus emociones, la experiencia estética ante la obra. ¿Por qué negar la educación estética?, ¿no puede ser igual de importante que la enseñanza histórico-artística? A nuestro juicio, el profesorado tendría que alentar al alumnado a que trasmita las impresiones causadas por la obra artística.

Por tanto, ¿cómo promover la educación estética en alumnado del MAEs? Nos basamos en el trabajo de Melo (2008) que, partiendo de las funciones estéticas desarrolladas por Leontiev (2000: 118), propone a sus estudiantes la contemplación y lectura de la obra de Bruegel El triunfo de la muerte (Museo Nacional del Prado, 1562-1563). Su objetivo es claro: "Entender como os não especialistas em arte processam a informação estética e que variáveis mobilizam nessa compreensão, reconhecendo a sua multiplicidade» (Melo, 2008: 19). Y serán justamente esas competencias estéticas las que nos conducen a las competencias críticas, necesarias para promover el pensamiento crítico entre el profesorado en formación.

Hemos considerado observar los tipos de apreciación artística y su aplicación en la educación museística propuestos por Funch (2000: 109-125): contemplación estética, empatía estética, comprensión artística, fascinación estética y experiencia estética como fenómeno trascendente. Por otra parte, quisiéramos proponer como uno de los aspectos a destacar en nuestro proyecto la perspectiva de género y la teoría feminista puesto que planten «un arte crítico, altamente teórico, que trataría de señalar los elementos retóricos e ideológicos que dentro de los discursos visuales construyen imágenes falsas e ideológicas de la mujer» (Pérez Carreño, 1995: 12). El propio Ryden declararía

El mundo sería un lugar mucho mejor si fuera centralizado desde una perspectiva feminista. [...]. Bueno, es como yo lo siento. Pienso que esas energías masculinas, competición y modificación del mundo natural y el patriarcado que ha causado tantos problemas en el mundo durante un par de miles de años y pienso que... Donald Trump es un buen ejemplo.

Por último, debemos hacer hincapié en que a través de la Estética Ryden podemos fomentar la coeducación audiovisual, entendida como el análisis de textos visuales desde la perspectiva de género (Belmonte, 2014: 150-151).

1.2.1. Objetivo con «F» de Estética Filosófica

Desarrollar la educación estética en la formación del profesorado. 
LAURA TRIVIÑO CABRERA

LA CÁMARA DE LAS MARAVILLAS DE MARK RYDEN: FORMACIÓN DEL PROFESORADO DE CIENCIAS SOCIALES EN EDUCACIÓN ESTÉTICA, CULTURA POPULAR Y LITERACIDAD CRÍTICA

\subsection{Con "P" de Patrimonio Audiovisual: sobre la postmodernidad, la "popular culture» y el pensamiento crítico}

En nuestro empeño por intentar llevar un currículum postmoderno a la educación superior decidimos afrontar un tercer reto: el patrimonio audiovisual. Por "patrimonio", el alumnado entiende "patrimonio material»; siendo este más valorado y, por consiguiente, por el que la ciudadanía siente una mayor concienciación. Sin embargo, existen otras nociones de patrimonios que no pueden ser obviadas. Hablamos del patrimonio audiovisual entendido como:

a) las grabaciones sonoras, radiofónicas, cinematográficas, de televisión, en vídeo y otras producciones que incluyen imágenes en movimiento y/o grabaciones sonoras, estén o no destinadas principalmente a la difusión pública;

b) los objetos, materiales, obras y elementos inmateriales relacionados con los medios audiovisuales, desde los puntos de vista técnico, industrial, cultural, histórico u otro; comprenden los materiales relacionados con las industrias cinematográfica, radiotelevisiva y de grabación, como las publicaciones, los guiones, las fotografías, los carteles, los materiales publicitarios, los manuscritos y creaciones diversas entre las que se cuentan los vestuarios y los equipos técnicos;

c) conceptos como la perpetuación de técnicas y entornos caídos en desuso asociados con la reproducción y presentación de esos medios (UNESCO, s. f.).

La obra de Ryden forma parte del Patrimonio Audiovisual, puesto que

por su capacidad de trascender las fronteras lingüísticas y culturales, atraer inmediatamente la vista y el oído, a las personas alfabetizadas y a las analfabetas, los documentos audiovisuales han transformado la sociedad al convertirse en un complemento permanente de los registros escritos tradicionales (UNESCO, 2017).

El alumnado del MAEs, al principio, se situó escéptico ante la obra de Ryden, manifestando que carecía de valor artístico, sobresaliendo su carácter comercial. La opinión generalizada era que Ryden no puede transmitir ninguna información, puesto que la cultura mediática no es considerada como una dimensión relevante para conocer nuestra realidad. Esto nos lleva hasta los términos "postmodernidad", la "popular culture» y el "pensamiento crítico». El rechazo a llevar al ámbito educativo la entendida como "popular culture» es, en cierto modo, denegar la posibilidad al alumnado de que estudie su propio presente, la sociedad postmoderna donde se halla. Y, con esto, llegamos a que, si impedimos como docentes que la cultura popular, cultura audiovisual, cultura mediática... sea abordada en las aulas, estaremos dejando que el alumnado se enfrente a esta sin el necesario pensamiento crítico que le permita asumir posibles manipulaciones, influencias, noticias falsas, prejuicios... insertos en los medios de comunicación de masas. 
LA CÁMARA DE LAS MARAVILLAS DE MARK RYDEN: FORMACIÓN DEL PROFESORADO DE CIENCIAS SOCIALES EN EDUCACIÓN ESTÉTICA, CULTURA POPULAR Y LITERACIDAD CRÍTICA

El problema se halla en que el profesorado en formación identifica como «arte» aquello que está respaldado por juicios de valor que diferencia entre las bellas artes y la cultura visual/popular/mediática. Existe una distinción entre historia del arte y la historia de la cultura visual, en la que la primera es sinónimo de calidad y enriquecimiento; y la segunda es sinónimo de manipulación y de colonización. Sin embargo, como docentes, debemos tener una perspectiva crítica de ambas. Y de ahí la importancia de incorporar el enfoque feminista, como hemos expuesto, en el apartado 1.2, puesto que la enseñanza de la historia del arte ha situado como genio creador al hombre; invisibilizando la obra de las mujeres artistas e, incluso, borrando su propia autoría, siendo suplantada por nombres de hombres artistas. Por tanto, a la vista de la exclusión de la otredad, ¿podemos seguir pensando que únicamente ese Arte es el único que tiene cabida en las aulas?

Por su parte, la cultura visual, independientemente de sus pretensiones comerciales y manipulativas, ¿debe ser obviada teniendo en cuenta que es esta justamente a la que el alumnado está más vinculado y que más conoce? Freedman (2006) formulará dos interrogantes para debatir la cuestión de la calidad en contextos educativos:

¿Qué arte vale la pena enseñar? (que no es lo mismo que ¿Qué arte es bueno?) y ¿Qué es lo más importante sobre el arte desde un punto de vista educativo, podemos conceptuar la calidad no como un gran valor (inherente), sino como una poderosa influencia (social)? (p. 85).

En Ryden, se entremezclan elementos claramente identificables, como expusimos en el apartado «justificación" de la cultura visual. Por tanto, su obra nos servirá para abordar la intersección de la enseñanza de arte y la cultura visual, explorando el significado de lo «cotidiano dentro del contexto pedagógico (Dias, 2016). Cuando un estudiante ve una obra de Ryden, por ejemplo, interpreta en un nivel primario la información, por ejemplo, qué tipo de objetos o de situación se representa. Pero más allá el estudiante debe desarrollar otros interpretantes que relacionen esa información con otra información relevante. Debe pensar, reflexionar, eso que ve.

Si tomamos los principios de la «Discipline-Based Art Education» (Getty Center for Arts Education, 1980, citado en Solberg, 2010: 1), que defiende la importancia de la educación a través del arte y persigue conseguir una "well-rounded view of art by studying any given work or type of work using four different disciplines, tailored to specific ages and grade levels»(Solberg, 2010: 1):

Art Production - Students learn skills and techniques in order to produce personal, original artwork.

Art History: Students study the artistic accomplishments of the past and present as motivation, examples of style or technique, and as discussion topics, especially in relation to cultural, political, social, religious, and economic events and movements. 
LA CÁMARA DE LAS MARAVILLAS DE MARK RYDEN: FORMACIÓN DEL PROFESORADO DE CIENCIAS SOCIALES EN EDUCACIÓN ESTÉTICA, CULTURA POPULAR Y LITERACIDAD CRÍTICA

Art Criticism: Students describe, interpret, evaluate, theorize and judge the properties and qualities of the visual form, for the purpose of understanding and appreciating works of art and understanding the roles of art in society.

Aesthetics: Students consider the nature, meaning, impact and value of art, are encouraged to formulate reflective, «educated» opinions and judgments about specific works of art, and examine criteria for evaluating works of art (Solberg, 2010: 1).

\subsubsection{Objetivo con «P» de Patrimonio Audiovisual}

Contemplar en el ámbito educativo tanto la enseñanza de la historia del arte como la historia de la cultura visual.

\section{Metodología}

Estamos ante un estudio de caso, una metodología cualitativa donde analizaremos los datos en función de las respuestas dadas por el alumnado. En relación a la muestra, nos hemos basado en $\mathrm{N}=44$ estudiantes que cursaban las asignaturas de Diseño y desarrollo de programaciones y actividades formativas y El currículum de Historia, Geografía, Arte y Filosofía del maEs (véase en el anexo, información detallada de los y las participantes). Con objeto de garantizar el rigor del estudio se aplicó la triangulación de métodos y técnicas.

\subsection{Fase I Investigación}

Se basa en la labor investigadora que nos permitió configurar el diseño de investigación educativa y el estudio de la obra de Mark Ryden.

\subsection{Fase II Implementación}

La fase II abarca dos momentos. El primer momento tiene lugar en el aula, cuando nos disponemos a situar al alumnado ante los contenidos teóricos sobre aspectos fundamentales para generar esas competencias críticas: concepto de cultura popular, literacidades y pensamiento crítico; y en qué consiste aprender en los museos (fase 2.1). En la fase 2.2, el alumnado realizó un breve comentario sobre "Saint Barbie» (1994) de Mark Ryden, una de las obras elegidas para la exposición La Cámara de las Maravillas. El motivo que nos llevó a elegir dicha obra fue la necesidad de conocer cómo se podían situar 44 estudiantes ante una misma obra, tras haber recibido formación sobre literacidades y la necesidad de sospechar. Además, hay que tener en cuenta que dicha obra podría tener diferentes lecturas. 
LA CÁMARA DE LAS MARAVILLAS DE MARK RYDEN: FORMACIÓN DEL PROFESORADO DE CIENCIAS SOCIALES EN EDUCACIÓN ESTÉTICA, CULTURA POPULAR Y LITERACIDAD CRÍTICA

\section{FIGURA 1}

Mark Ryden (1994). Saint Barbie. Colección particular

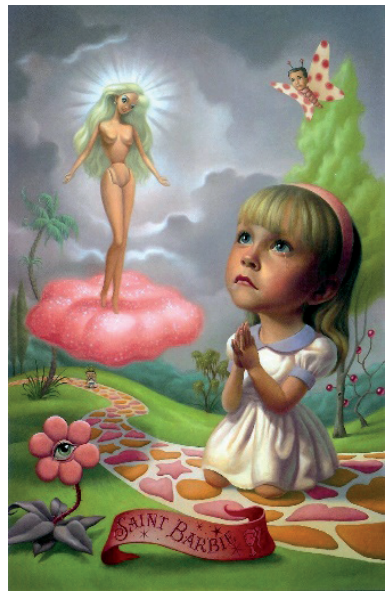

Dicho comentario debía realizarse sin conocer al autor, el sentido de la exposición ni de la propia obra. Queríamos obtener datos sobre el conocimiento tácito del alumnado, entendido como

Um conjunto de proposiçoes que versam aspectos da História, construídas a partir de uma pluralidade de experiências pessoais idiossincráticas e sociais, e ou mediatizadas pela fruiçao de artefactos expressivos e comunicativos. O adjectivamte tácito debe-se ao facto dos individuos nâo reconhecerem ese conhecimento como independente e/ou concorrente do conhecimento científico ou curricular (Melo, 2009: 15).

Para el análisis de las respuestas del alumnado, se han tenido en cuenta los Estadios Estéticos de Housen (2000: 154-155) puesto que nos interesaba conocer de qué manera el alumnado se aproximaba a una obra de un artista que no conocía, desde sus diferentes especialidades (Historia, Filosofía, Arte y Educación):

- Estadio I. Observadores/as narrativos/as son contadores/as de historias.

- Estadio II. Observadores/as constructivos/as comienzan a construir una estructura para mirar las obras de arte usando las herramientas más lógicas y accesibles; sus propias percepciones, y su conocimiento del mundo natural y los valores del mundo social, moral y convencional.

- Estadio III. Observadoras/es clasificadoras/es adoptan la actitud analítica o crítica del historiador/a del arte.

- Estadio IV. Observadoras/es interpretativas/os buscan un contacto personal con la obra de arte. 
LA CÁMARA DE LAS MARAVILLAS DE MARK RYDEN: FORMACIÓN DEL PROFESORADO DE CIENCIAS SOCIALES EN EDUCACIÓN ESTÉTICA, CULTURA POPULAR Y LITERACIDAD CRÍTICA

- Estadio V. Observadoras/es recreativos/as, con una larga historia de mirar y reflejar sobre obras de arte, ahora voluntariamente dudan (Housen, 2000: 154-155, traducción nuestra).

El segundo momento está constituido por seis actividades. Antes de visitar la exposición y explicar la obra de Ryden, en el exterior, invitamos al alumnado a tomar un post-it (amarillo) y escribir una palabra que definiera la exposición sin haberla visto, teniendo en cuenta únicamente como referencia Saint Barbie, cuadro que habían comentado en clase, en la sesión previa.

FIGURA 2

Ejemplos de post-it (Post-Verde y Pre-Amarillo) de comentarios previos y posteriores de tres estudiantes (2017)

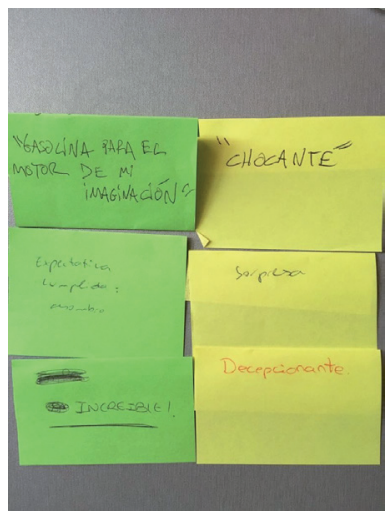

FUENTE: Laura Triviño Cabrera.

Para analizar las concepciones del alumnado, previas y posteriores a la visita a la exposición, decidimos tomar las funciones del arte y la educación estética determinadas por Leontiev para la disciplina pictórica, puesto que quisimos averiguar si, ante una obra cuya temática fundamental es la cultura visual y la época actual, las concepciones cambian antes y después de la visita:

- Emocional: palabras y juicios que transmiten sensaciones y sentimientos provocados por el cuadro, su evaluación general y emocional.

- Orientación para la vida: palabras y juicios que describen las pinturas como una pieza de vida real, una situación desarrollada en el tiempo.

- Estilística: palabras y juicios referidos a medios y esquemas artísticos revelando su función y realzando peculiaridades del estilo.

- De síntesis: interpretación del contenido del cuadro y su significado, pensamientos y sentimientos de personajes. 
LA CÁMARA DE LAS MARAVILLAS DE MARK RYDEN: FORMACIÓN DEL PROFESORADO DE CIENCIAS SOCIALES EN EDUCACIÓN ESTÉTICA, CULTURA POPULAR Y LITERACIDAD CRÍTICA

- Asociativa: asociaciones sobre diferentes temas provocadas por el cuadro y su significado.

- Orientada para el Autor: palabras y juicios indicando la intención, estado psicológico y contexto biográfico del autor (Leontiev, 2000: 136, traducción nuestra).

La segunda de ellas se desarrolló en el exterior del CAC y consistió en una breve presentación sobre quién es Ryden, el sentido de su obra y el contexto en el que se halla; así como dar a conocer la obra de su esposa, la artista Marion Peck. Es importante señalar la elaboración de una presentación en power point que fue imprimida en tamaño A3 y expuesta ante el alumnado fuera del CAC, dado que en su interior debíamos permanecer en silencio.

Asimismo, expuesta la explicación sobre Ryden; accedimos a la exposición, dejando tiempo para que el alumnado por sí mismo contemplase libremente la exposición, pero dejándoles un encargo. Durante la fase 2 , les comenté que tenían que elegir una obra de la exposición y llevar a cabo una propuesta de actividades que desarrollarían con alumnado de ESO o Bachillerato, en el hipotético caso de que tuvieran la oportunidad de visitar con sus estudiantes la misma exposición que ellos y ellas observarían junto conmigo.

Organicé la visita de una forma que el alumnado no había podido experimentar. Observaban las obras de forma individual, en otras ocasiones, en grupos pequeños, conversaban y hubo momentos de experiencia estética como fenómeno trascendente (Funch, 2000: 122), cuando algunos/as alumnos/as, público visitante y el/la docente, delante de la obra Aurora, conversábamos sobre qué podría estar diciéndonos y cuáles eran las emociones que nos transmitían.

Al término de la visita, reuní al alumnado y les invité a que se atrevieran a comentarle al resto de compañeros/as qué obra habían elegido y qué pensaban sobre ella; creándose, así, un espacio reflexivo que ahondaba fundamentalmente en las emociones causadas por la obra para decidir su elección, así como su posible vinculación con conocimientos históricos, artísticos o filosóficos, dependiendo de la especialidad de cada estudiante. Un total de cuatro estudiantes comentaron la obra elegida:

- egh 36 y eh 30, ambos historiadores, eligieron la misma obra, Sophia's Bubbles, y decidieron compartir juntos los motivos de su elección ante el resto de compañeros/as.

- $e a b_{m}$ 37, como historiador del arte y licenciado en Bellas Artes, manifestó las relaciones entre diferentes artistas que se han detenido en la figura de Venus y su posible conexión con Snow White de Mark Ryden.

- eh 22, historiadora del arte, decidió explicar cómo había ampliado su visión de la exposición (era la segunda vez que visitaba Cámara de las Maravillas), concretamente, de Allegory of the Four Elements.

Tras la visita a la exposición, el alumnado volvió a tomar un post-it (verde), donde volverían a escribir una palabra que definiera dicha exposición tras haberla visitado. 


\subsection{Fase III Evaluación}

Por último, tendríamos la fase III Evaluadora, en la que hemos designado como "reflexión final». En la fase 3.1, el alumnado tenía que entregar un trabajo individual en el que, tras la elección de una obra de la exposición, debían desarrollar una serie de actividades que planificarían con el alumnado. Estas actividades tenían que emplear la metodología de aprendizaje con objetos (Hooper-Greenhill, 1991) a través de las preguntas de memoria, convergentes, divergentes y críticas; e identificar qué estilos de aprendizaje, basado en el Modelo 4 MAT de Bernice McCarthy (2007), potenciarían a través de la obra de Ryden (imaginativo, analítico, sentido práctico y/o dinámico-creativo). No obstante, antes tendrían que justificar el motivo de su elección y responder a las tres preguntas que configuran la metodología "Estrategias del Pensamiento Visual» (Visual Thinking Strategies): ¿Qué está sucediendo en esta imagen?, ¿Qué ves que te hace pensar/decir eso?, ¿Qué más puedes/podemos encontrar? Nos interesaba conocer si, después de la visita al CAC, el profesorado en formación tendría como meta la necesidad de abordar las apreciaciones estéticas y críticas en la elección de la obra de Ryden. Para ello, nos basamos en los tipos de apreciación artística y su aplicación en la educación museística de Funch.

- Contemplación estética (apreciación visual del arte): "Capacidad espontánea que no necesita de formación previa» (Funch, 2000: 111).

- Empatía estética (apreciación emocional del arte): "sentimiento que se experimenta como si se perteneciese a otra persona u objeto» (Funch, 2000: 112).

- Comprensión artística (apreciación cognitiva del arte): «Apreciación cognitiva del arte parece ser el tipo de apreciación artística más altamente considerado, según la literatura y actividades educativas producidas hoy en día» (Funch, 2000: 113).

- Fascinación estética: "Una atracción que generalmente dura un período más largo en el tiempo y cada contacto da origen a un sentimiento agradable de confort, también designado por placer catártico. [...]. El espectador se siente relajado, tal como si una persona se sintiese aliviada de presiones internas» (Funch, 2000: 119).

- Experiencia estética como fenómeno trascendente: «En las artes visuales, el momento estético es aquel instante pasajero, de tal modo breve que parece casi intemporal, cuando el espectador está en unísono con la obra de arte para la cual él está mirando o como realidad de un género que el propio espectador ve en términos de arte, como forma y color. Él deja de ser su propio yo común y el cuadro, edificio, estatua, paisaje o realidad estética deja de estar fuera de sí. Los dos se vuelven una identidad. El tiempo y el espacio desaparecen y el espectador es poseído de una única consciencia» (Berenson, 1948: 84, citado en Funch, 2000: 122, traducción nuestra). 
LA CÁMARA DE LAS MARAVILLAS DE MARK RYDEN: FORMACIÓN DEL PROFESORADO

DE CIENCIAS SOCIALES EN EDUCACIÓN ESTÉTICA, CULTURA POPULAR Y LITERACIDAD CRÍTICA

En cuanto a la fase 3.2, el alumnado tuvo que evaluar la asignatura a nivel general; dos de los ítems fueron destinados a la visita a la exposición, cuyos resultados fueron altamente satisfactorios.

\section{RESUlTADOS}

\subsection{Alicia se atrevió a sospechar. Conocimiento tácito sobre Saint Barbie}

En esta primera actividad, vamos a comprobar de qué manera el alumnado se acerca a una obra de arte, como es Saint Barbie (1994) de Mark Ryden. Como puede verse en el gráfico, los alumnos se decantan más por el Estadio IV, desarrollan observaciones interpretativas; mientras que las alumnas presentan un equilibrio a la hora de pertenecer a los diferentes estadios, siendo el más destacable el Estadio IV y el menos, el Estadio III, sobre observación clasificadora al adoptar la actitud analítica del historiador/a del arte. De hecho, es justamente este estadio al que pertenece mayoritariamente el alumnado licenciado o graduado en Historia del Arte. En el caso de alumnado licenciado o graduado en Filosofía, el estadio más repetido es el III, interpretativo.

GRÁFICO 1

Estadios para Saint Barbie (2017)

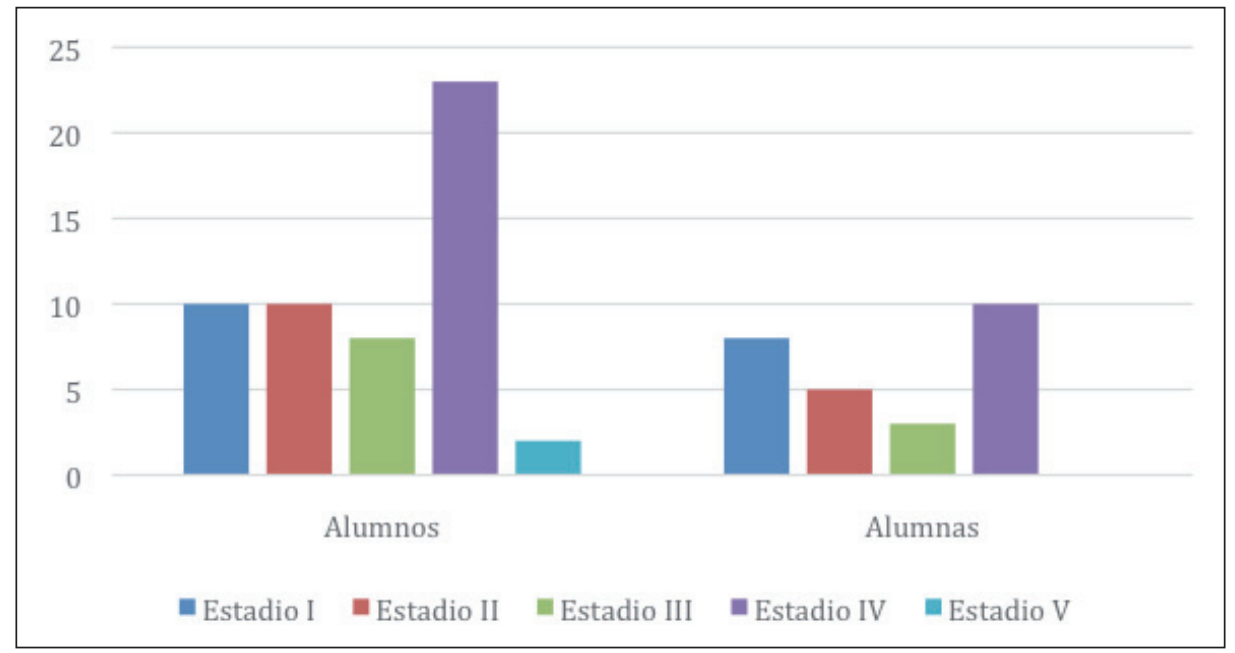

FuENTE: Laura Triviño Cabrera.

Asimismo, nos interesaba conocer si, en el comentario del alumnado, podría apreciarse una reflexión crítica, dado que previamente habíamos abordado el enfoque feminista en clase, concretamente la coeducación audiovisual, dentro de 
LA CÁMARA DE LAS MARAVILLAS DE MARK RYDEN: FORMACIÓN DEL PROFESORADO DE CIENCIAS SOCIALES EN EDUCACIÓN ESTÉTICA, CULTURA POPULAR Y LITERACIDAD CRÍTICA

la necesidad de desarrollar múltiples literacidades, incidiendo en el pensamiento crítico y en la actitud de sospecha ante los roles y los estereotipos visuales.

GRÁFICO 2

Enfoque feminista para Saint Barbie (2017)

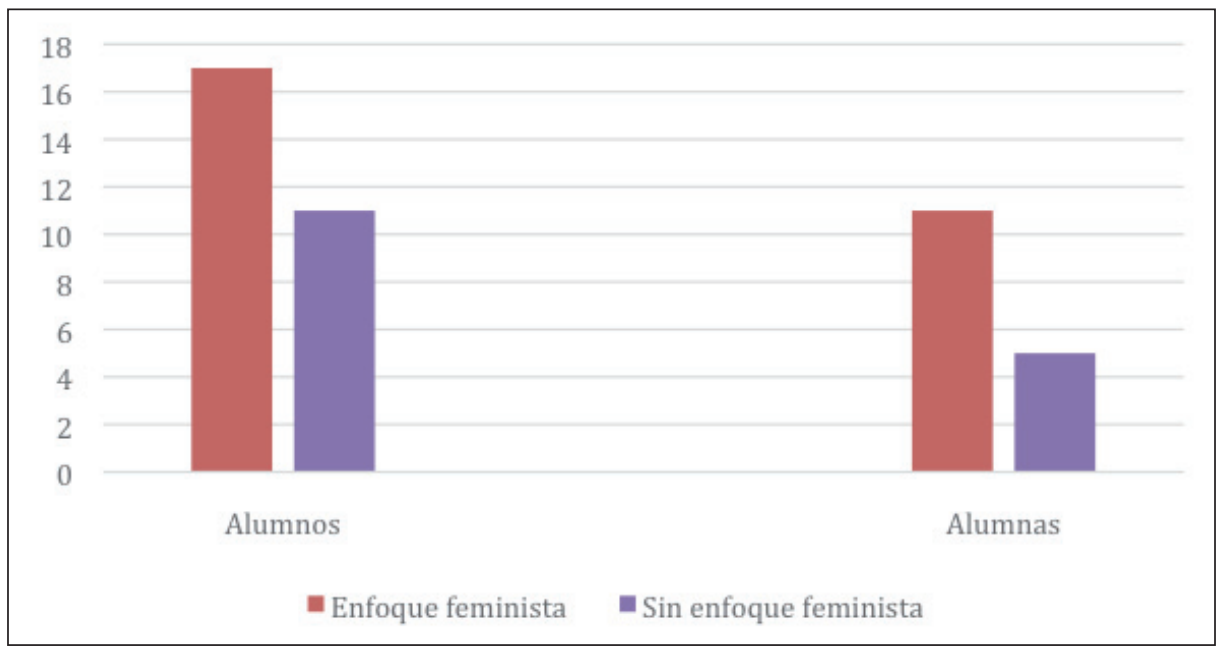

FuENTE: Laura Triviño Cabrera.

Las $3 / 4$ partes del alumnado femenino fueron conscientes de la lectura feminista de la obra de Ryden. En el caso del alumnado, aunque no alcanzó el mismo porcentaje, una amplia mayoría de alumnos también se percató de ello. 
LA CÁMARA DE LAS MARAVILLAS DE MARK RYDEN: FORMACIÓN DEL PROFESORADO DE CIENCIAS SOCIALES EN EDUCACIÓN ESTÉTICA, CULTURA POPULAR Y LITERACIDAD CRÍTICA

GRÁFICO 3

Enfoque feminista, según alumnas, para Saint Barbie (2017)

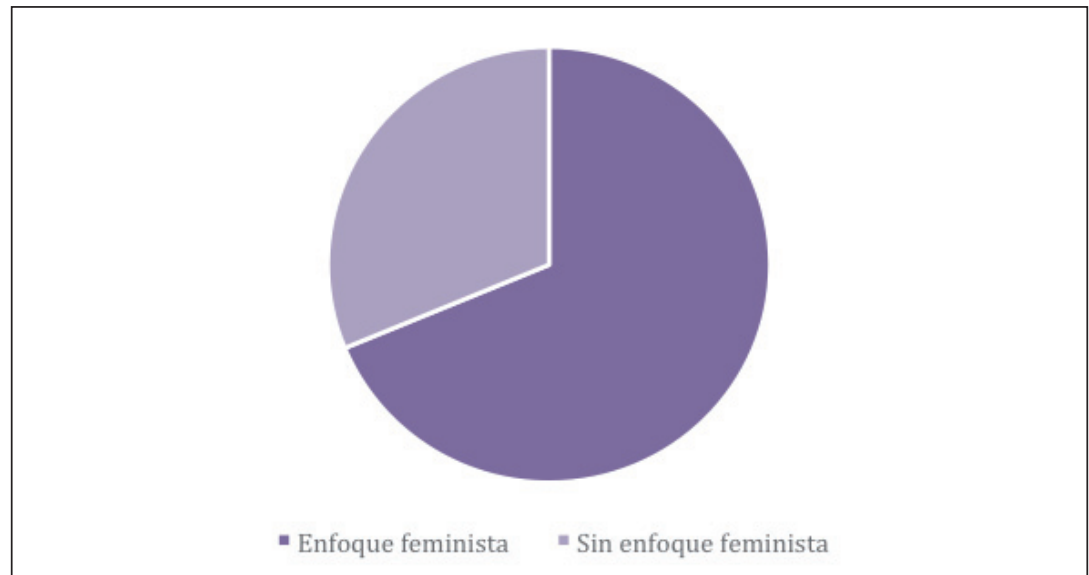

FuENTE: Laura Triviño Cabrera.

GRÁFICO 4

Enfoque feminista, según alumnos, para Saint Barbie (2017)

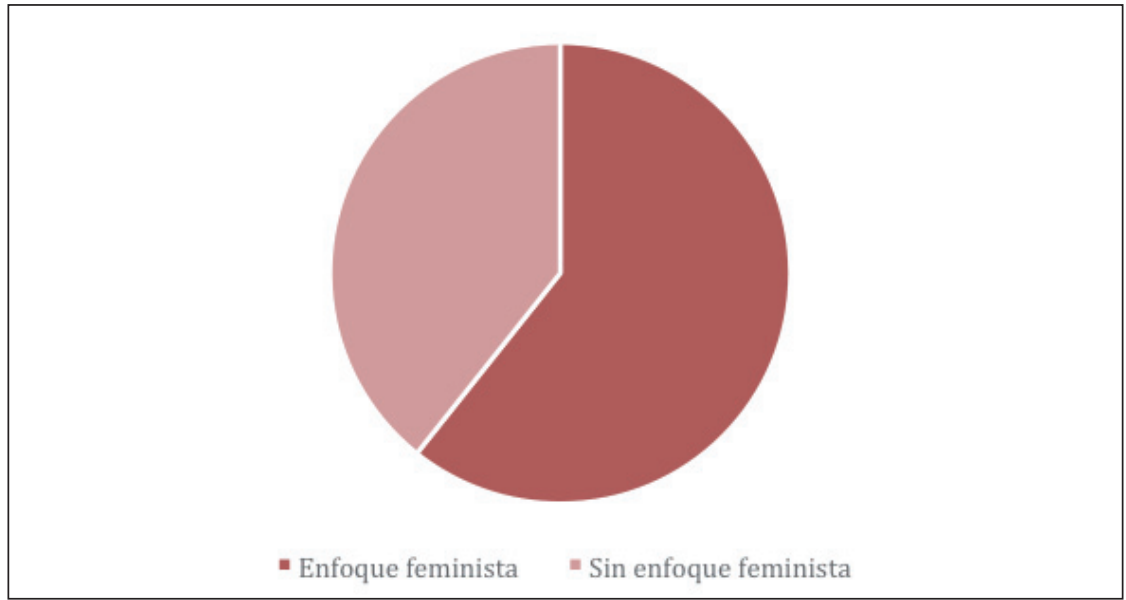

FuENTE: Laura Triviño Cabrera.

Por último, hemos visto conveniente establecer cuántos de los comentarios abordan un tema común. Pues bien, hemos determinado que, en un alto porcentaje, 
LA CÁMARA DE LAS MARAVILLAS DE MARK RYDEN: FORMACIÓN DEL PROFESORADO DE CIENCIAS SOCIALES EN EDUCACIÓN ESTÉTICA, CULTURA POPULAR Y LITERACIDAD CRÍTICA

el alumnado estuvo de acuerdo en que existe una crítica hacia el consumismo, la sociedad capitalista y los medios de comunicación.

GRÁFICO 5

La crítica de Saint Barbie (2017)

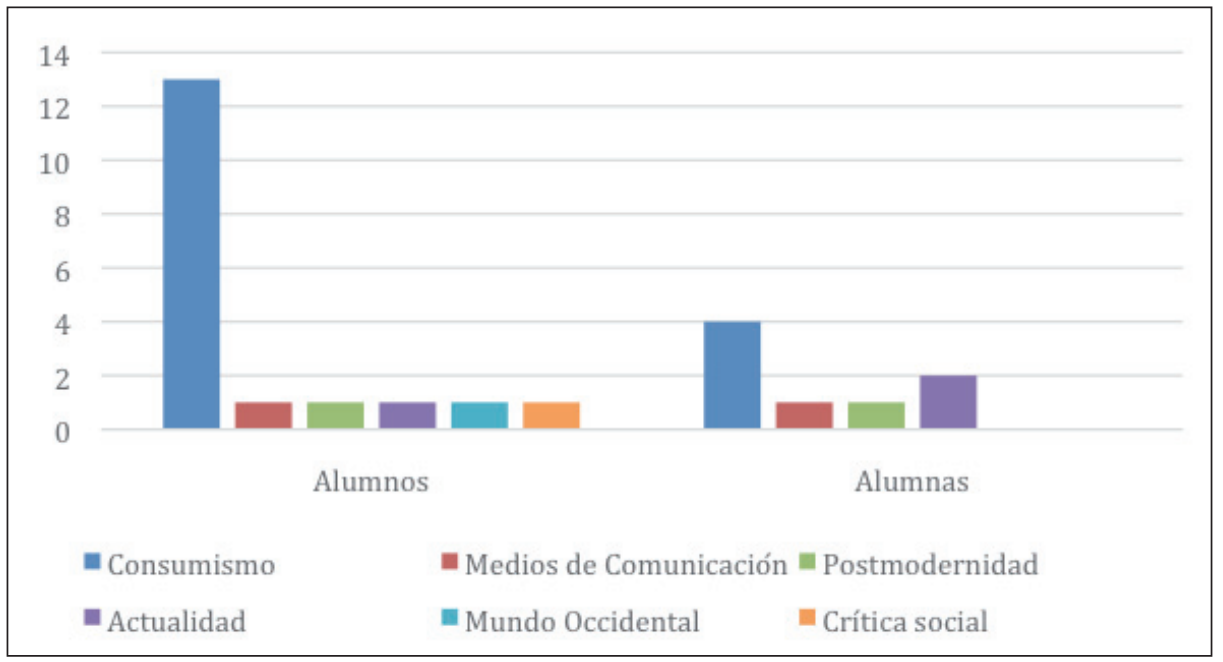

FUENTE: Laura Triviño Cabrera.

\subsection{Post-it: conocimiento tácito (una palabra previa) y conocimiento de/constructivo (una palabra post)}

Como puede observarse en los gráficos, en relación a las concepciones fijadas por Leontiev para la pintura, el alumnado mostró una mayor inclinación a deducir impresiones estilísticas antes de la visita; mientras que las palabras emocionales se incrementaron tras contemplar la exposición. 
LAURA TRIVIÑO CABRERA

LA CÁMARA DE LAS MARAVILLAS DE MARK RYDEN: FORMACIÓN DEL PROFESORADO DE CIENCIAS SOCIALES EN EDUCACIÓN ESTÉTICA, CULTURA POPULAR Y LITERACIDAD CRÍTICA

GRÁFICO 6

Post-it palabra previa (2017)

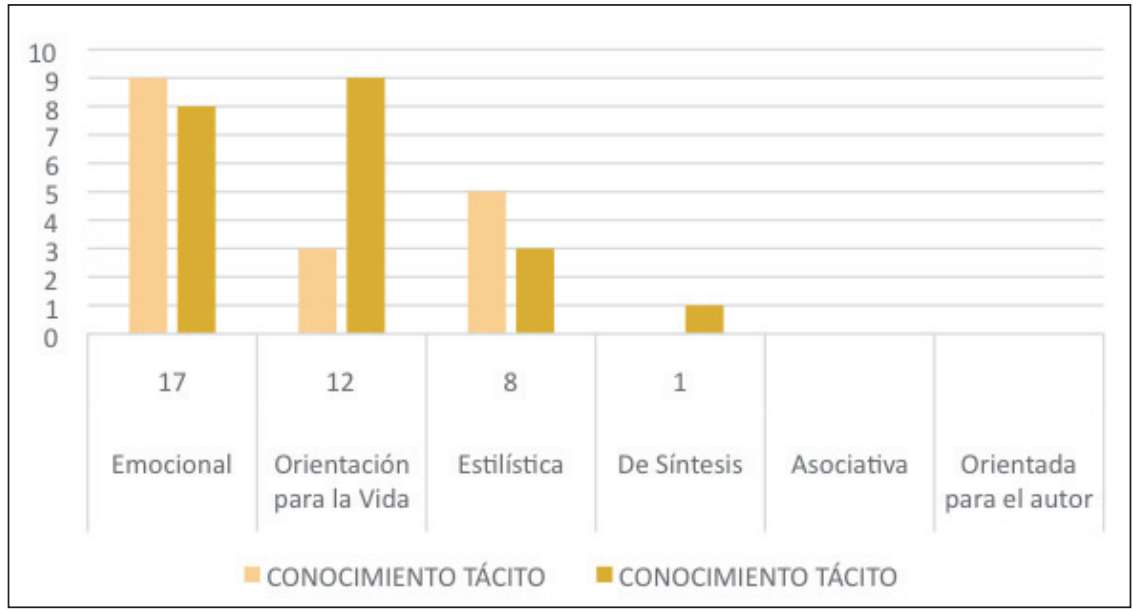

FuENTE: Laura Triviño Cabrera

GRÁFICO 7

Post-it palabra post (2017)

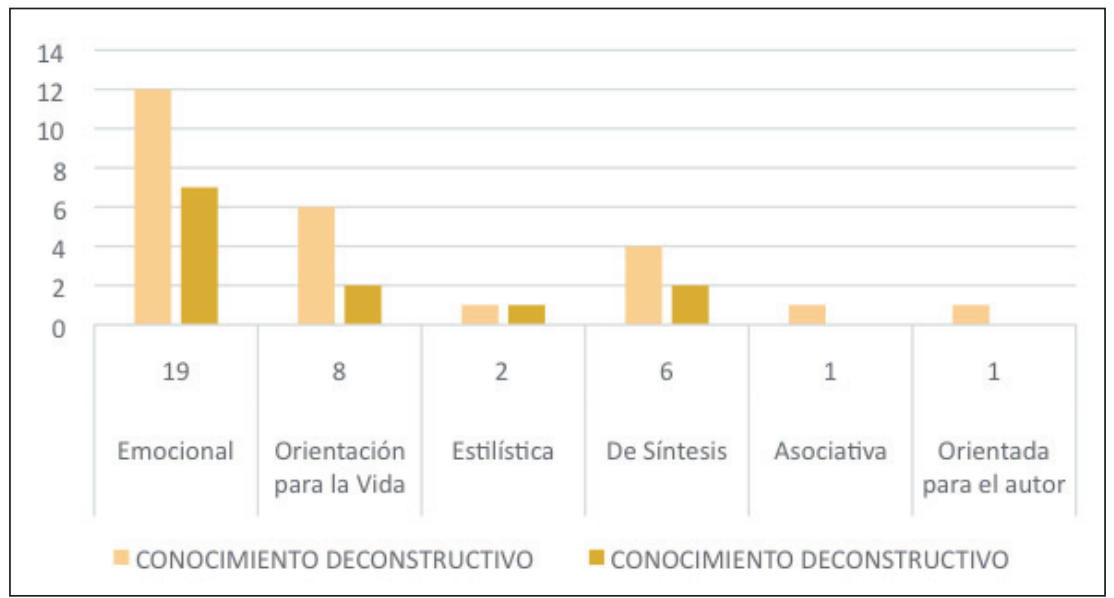

FuENTE: Laura Triviño Cabrera. 
LAURA TRIVIÑO CABRERA

LA CÁMARA DE LAS MARAVILLAS DE MARK RYDEN: FORMACIÓN DEL PROFESORADO DE CIENCIAS SOCIALES EN EDUCACIÓN ESTÉTICA, CULTURA POPULAR Y LITERACIDAD CRÍTICA

GRÁFICO 8

Post-it pre y post para alumnas (2017)

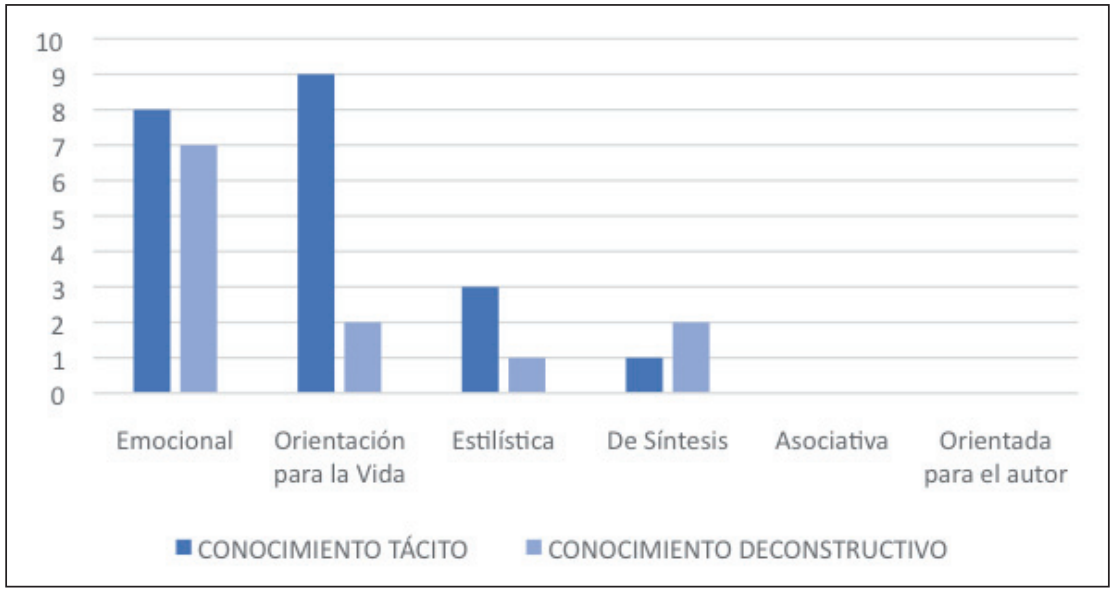

FuENTE: Laura Triviño Cabrera.

GRÁFICO 9

Post-it pre y post para alumnos (2017)

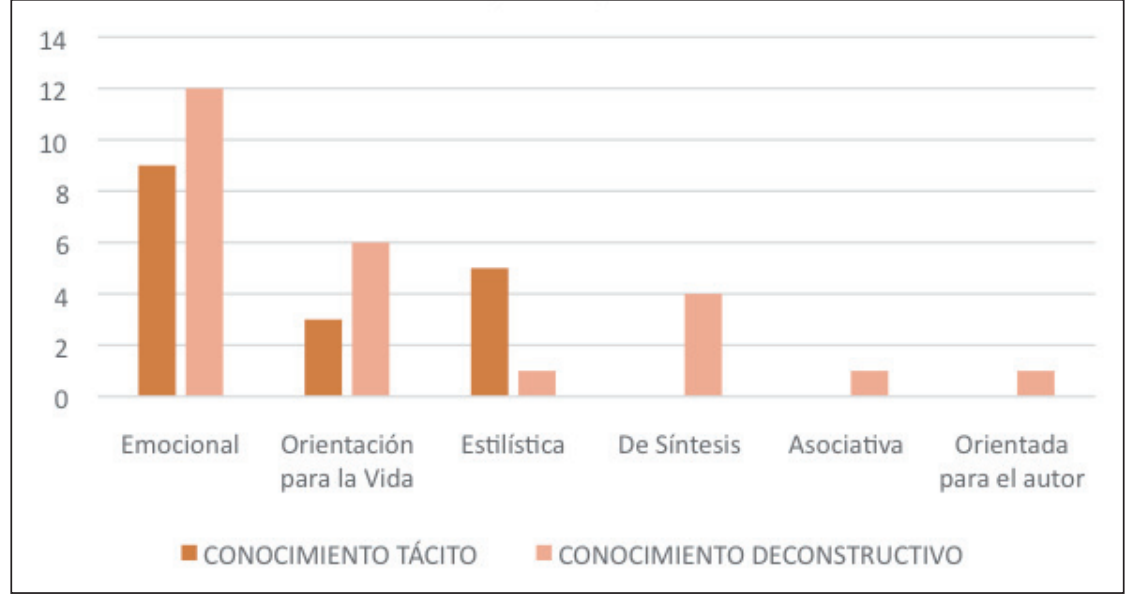

FUENTE: Laura Triviño Cabrera.

Creemos que uno de los aspectos más importantes que se deducen de la recogida de datos es que el alumnado que llegó con prejuicios y rechazo hacia la obra de Ryden cambió su parecer tras la contemplación de la exposición. 
LA CÁMARA DE LAS MARAVILLAS DE MARK RYDEN: FORMACIÓN DEL PROFESORADO

DE CIENCIAS SOCIALES EN EDUCACIÓN ESTÉTICA, CULTURA POPULAR Y LITERACIDAD CRÍTICA

Además, hay que tener presente como los aspectos negativos fueron más señalados por estudiantes de Historia del Arte, un dato nada despreciable puesto que conciben la cultura visual o cultura popular fuera del concepto Arte. He aquí una recopilación de todas las palabras, antes y después, cuando se tornaron positivas:

TABLA 1

Emociones previas y post (2017)

\begin{tabular}{|c|c|c|}
\hline ESTUDIANTE & POST-IT PALABRA PREVIA & POST-IT PALABRA POST \\
\hline $\mathrm{EA}_{\mathrm{m}} 7$ & Comercial & Inteligente \\
\hline $\mathrm{EHm} 8$ & Polémico & Esclarecedor \\
\hline $\mathrm{EH}_{\mathrm{f}} 10$ & Extraño & Impresionante \\
\hline $\mathrm{EF}_{\mathrm{m}} 24$ & Esperpento & Crítica \\
\hline $\mathrm{EH}_{\mathrm{f}} 26$ & Crítica reflexiva & Supera expectativas \\
\hline $\mathrm{EH}_{\mathrm{m}} 31$ & Chocante & Increíble \\
\hline $\mathrm{EH}_{\mathrm{f}} 35$ & Decepcionante & Bonito \\
\hline $\mathrm{EF}_{\mathrm{m}} 40$ & Insulso & \\
\hline
\end{tabular}

FUENTE: Laura Triviño Cabrera.

Por otro lado, el alumnado que llegó con una mentalidad abierta a la exposición y empleó palabras positivas hacia la Estética Ryden no cambió su parecer, e incluso le condujo a declarar que dicha muestra superó sus expectativas.

\begin{tabular}{|c|c|c|}
\hline ESTUDIANTE & POST-IT PALABRA PREVIA & POST-IT PALABRA POST \\
\hline $\mathrm{EF}_{\mathrm{m}} 2$ & Sorpresa & Expectativa cumplida: asombro \\
\hline $\mathrm{EH}_{\mathrm{f}} 3$ & Asombrosa & Asombroso y fascinante \\
\hline $\mathrm{EH}_{\mathrm{f}} 5$ & Crítica de la actualidad y reivindicación & Innovadora e interesante \\
\hline $\mathrm{EH}_{\mathrm{f}} 19$ & Impresionante e impactante & Mágico e impresionante \\
\hline $\mathrm{EH}_{\mathrm{f}} 21$ & Diferente & Revelador \\
\hline $\mathrm{EH}_{\mathrm{f}} 26$ & Crítica reflexiva & Supera expectativas \\
\hline $\mathrm{EH}_{\mathrm{f}} 41$ & Reivindicación & Realismo \\
\hline
\end{tabular}

Otro dato importante es cómo el alumnado procedente de las titulaciones de historia del arte e historia utilizó palabras estilísticas antes de observar la exposición, fruto de sus conocimientos disciplinares; para, posteriormente, cambiarlas por palabras que aludiesen a lo emocional. 
LAURA TRIVIÑO CABRERA

LA CÁMARA DE LAS MARAVILLAS DE MARK RYDEN: FORMACIÓN DEL PROFESORADO DE CIENCIAS SOCIALES EN EDUCACIÓN ESTÉTICA, CULTURA POPULAR Y LITERACIDAD CRÍTICA

TABLA 2

Estilística versus emoción (2017)

\begin{tabular}{|c|c|c|}
\hline ESTUDIANTE & $\begin{array}{c}\text { POST-IT PALABRA PREVIA } \\
\text { CORRESPONDIENTE A ESTILÍSTICA }\end{array}$ & $\begin{array}{c}\text { POST-IT PALABRA POST } \\
\text { CORRESPONDIENTE A EMOCIÓN }\end{array}$ \\
\hline $\mathrm{EH}_{\mathrm{m}} 12$ & Alegórico & Disfrutable \\
\hline $\mathrm{EA}_{\mathrm{f}} 17$ & Surrealista & Novedosa \\
\hline $\mathrm{EA}_{\mathrm{m}} 28$ & Simbolismo & Perturbador \\
\hline $\mathrm{EH}_{\mathrm{m}} 30$ & Moderno & Maravilloso \\
\hline $\mathrm{EH}_{\mathrm{m}} 45$ & Alegoría & Atrayente \\
\hline
\end{tabular}

FuENTE: Laura Triviño Cabrera.

\subsection{Ryden y la Educación Estética. Elección de la obra de Ryden para desarrollar actividades con alumnado ESO/Bachillerato}

Los datos revelan que el alumnado está habituado a la función de «comprensión artística"; es donde se encuentra más cómodo y donde se reconoce mejor puesto que la Historia del Arte les ha sido enseñada teniendo en cuenta estilos artísticos y técnicas. Sin embargo, situarlos ante una obra de la cultura popular les lleva a admitir su preferencia desde otras funciones. Tanto para las alumnas como para los alumnos, tras la comprensión artística, la elección puede ser determinada por el siguiente orden: "contemplación estética", "fascinación estética", "experiencia estética como fenómeno trascendente» y «empatía estética».

\section{GRÁFICO 10}

Ryden y la Educación Estética (2017)

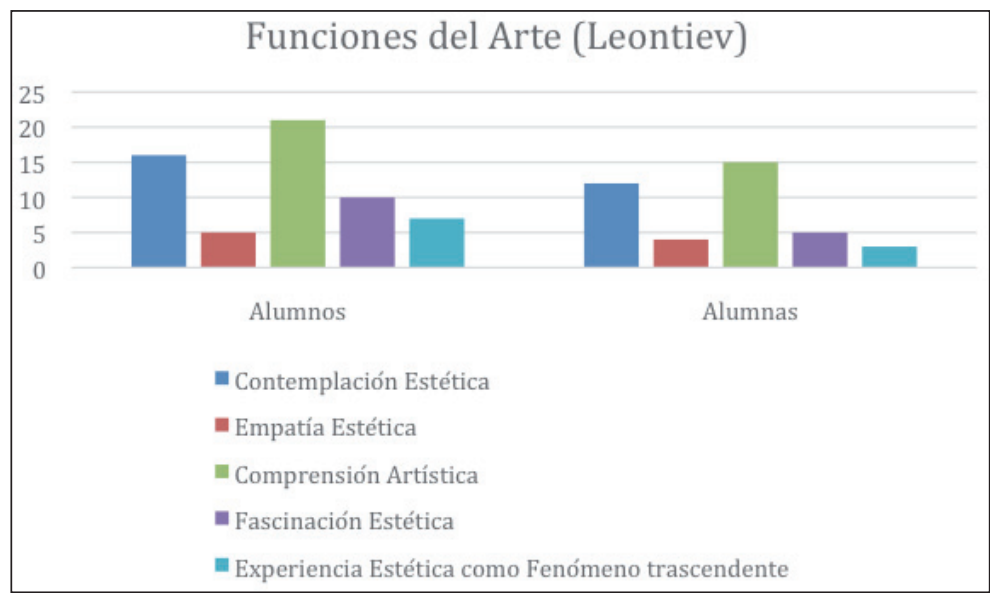

FUENTE: Laura Triviño Cabrera. 
LA CÁMARA DE LAS MARAVILLAS DE MARK RYDEN: FORMACIÓN DEL PROFESORADO DE CIENCIAS SOCIALES EN EDUCACIÓN ESTÉTICA, CULTURA POPULAR Y LITERACIDAD CRÍTICA

Por tanto, en menor o en mayor medida, el alumnado se desprendió de ese currículum oficial donde la categoría Arte solo puede ser analizada o elegida por juicios de calidad; y se contemplaron muchos más aspectos, como la crítica a la sociedad o el gusto estético del profesorado en formación y las posibilidades educativas de las emociones en la elección de las obras.

\section{DiSCUSIÓN Y LIMITACIONES DE LA INVESTIGACIÓN}

La presente investigación educativa ha supuesto todo un reto al enfrentarnos a una clase de estudiantes que se preparan para ser docentes de ESO y de Bachillerato y que entran en dicho máster, muy desmotivados/as, considerando que se trata de un mero trámite. Resulta difícil intentar que un alumnado condicionado por un currículum oculto/invisible, por su papel pasivo como estudiante durante toda su trayectoria académica, consiga sospechar e interesarse por temas que hasta ahora habían quedado fuera de las aulas como es la cultura mediática o audiovisual. Para ello, nuestro papel como docentes debía ser justamente inverso al que ellos/as tenían concebido desde su experiencia discente.

\subsection{Con "E» de educación}

El alumnado valoró positivamente en las evaluaciones de la asignatura, la visita al Centro de Arte Contemporáneo. ¿Podemos considerar la cultura visual o popular dentro de las enseñanzas sobre historia del arte, arte y filosofía? Así fue, no hubo ningún estudiante que pensara, al final de su visita, lo contrario. Por tanto, pese al escepticismo previo, el profesorado en formación consideró relevante el estudio de la Estética Ryden.

\subsection{Con "F» de estética filosófica}

El alumnado del máster se situó por primera vez ante una obra de forma emocional, donde pudieran ser expuestas impresiones y sus propias subjetividades. Se potenció que el alumnado se atreviera a opinar y ante la falta de costumbre en el análisis de obras procedentes de la cultura visual, recurrió a los sentimientos provocados por dicha obra. Esto le llevaría a presentar ante sus compañeras/os la elección de la obra escogida para planificar actividades desde sus propias emociones y el placer estético provocadas por estas; añadiendo las posibles conexiones con temas importantes para la enseñanza de las disciplinas y la vinculación con otras obras de arte. Aquí debemos incidir en cómo tras la exposición el interés por la obra de Ryden aumentó, llegando algunos/as estudiantes de forma voluntaria a seguir comentando aspectos de la exposición de este artista en el foro de la asignatura. 
LA CÁMARA DE LAS MARAVILLAS DE MARK RYDEN: FORMACIÓN DEL PROFESORADO DE CIENCIAS SOCIALES EN EDUCACIÓN ESTÉTICA, CULTURA POPULAR Y LITERACIDAD CRÍTICA

La reflexión crítica de la Estética Ryden conduce directamente a la necesidad de una "coeducación audiovisual", a través de la cual el alumnado sea consciente de la perspectiva de género en la lectura de imágenes. Como puede verse, en el análisis de los datos, la mayor parte del alumnado señaló como punto fundamental de Saint Barbie los marcados estereotipos y roles de género para las niñas; y es de destacar que, en dos casos, dos alumnos denunciaron las exigencias de cumplir una serie de roles y de estereotipos para los hombres que enfatizan la masculinidad hegemónica.

Entre las limitaciones de la investigación, observamos que nuestros resultados son subjetivos como la propia profesora Melo (2008) explica, existen múltiples interpretaciones y todas necesitan ser atendidas para dar una explicación de lo que las obras significan y de cómo son de hecho interpretadas. Por otra parte, no pretenden su generalización dado que todo el proyecto parte de la percepción estética de cada uno/a de los/as estudiantes concretos. Por otra parte, quedaría pendiente generar nuevas hipótesis que puedan ser contrastadas con nuevos grupos que nos permitan proceder a un diagnóstico para su intervención.

Por otra parte, no se trataba tanto de ver las influencias o de las técnicas empleadas, sino situarse ante la contemplación estética, la empatía estética, la fascinación estética y la experiencia estética. Si en un primer nivel conseguíamos esto, posteriormente, se podía dar el paso para que el alumnado fuera consciente de que toda obra de Ryden tiene una influencia artística detrás y he aquí ese momento de comprensión artística.

Para finalizar, quisiéramos señalar que uno de los aspectos más destacables por parte del alumnado en relación a su visita a la exposición de Mark Ryden es la superación de las expectativas. Freedman afirmaba que esta percepción confirma la importancia de las emociones en el aprendizaje: "El arte que les desafía a considerar su propia relación con éste y promueve una respuesta de sorpresa intelectual, crea nuevas expectativas, lo que ilustra la conexión entre emoción y cognición» (Freedman, 2006: 97).

\subsection{Con "P» de patrimonio audiovisual}

A través de la reflexión previa del alumnado sobre Saint Barbie, la mayor parte del alumnado dedujo que estábamos ante una crítica al consumismo y a la sociedad actual: "La visita y posterior actividad de Mark Ryden, ya que nos hacía que pudiéramos especular sobre cualquier cuestión que nos suscitase inquietudes o desconocimiento (EHEPm15)». Mediante la realización de un trabajo donde tendrían que planificar diferentes actividades, cuyo eje fundamental fuera el estudio de una obra contemporánea con alusiones e influencias sobre movimientos artísticos anteriores, así como del arte actual. Como docente, el alumnado planificó en sus actividades las posibilidades que ofrecían para que sus futuros/as estudiantes deconstruyeran los mensajes que les llegan desde las redes sociales y los medios de comunicación de masas y comprendieran problemas sociales, políticos, económicos, religiosos, etc., a través del desarrollo de diferentes literacidades. 
LA CÁMARA DE LAS MARAVILLAS DE MARK RYDEN: FORMACIÓN DEL PROFESORADO DE CIENCIAS SOCIALES EN EDUCACIÓN ESTÉTICA, CULTURA POPULAR Y LITERACIDAD CRÍTICA

Solo podría concluir con las propias palabras de mi alumnado que ejemplifican qué ha significado este proyecto y cómo, a través de una serie de estrategias educativas, hemos conseguido el objetivo principal que nos propusimos: el desarrollo de competencias críticas que están ligadas a las estéticas y audiovisuales. De todas las percepciones del alumnado, nos resultan especialmente significativas las de un alumno historiador del arte muy escéptico con la obra de Ryden. Se trata de un punto de vista resultante de cómo la enseñanza de la Historia del Arte desde juicios de valor elimina el papel activo del alumnado en su construcción del propio conocimiento, en el que entran en juego sus ideas previas, sus emociones, sus sospechas y su contexto.

Tras haber visitado la exposición [...] tengo que reconocer que ha cambiado mi opinión sobre el artista. En el post-it que todos los alumnos rellenamos antes de entrar al espacio con una palabra que definiera lo que esperábamos encontrarnos yo escribí "comercial» y es precisamente desde este concepto desde el que me gustaría empezar el comentario. [...]. el artista americano venía avalado por una trayectoria plagada de imágenes agradables, próximas a la cultura popular, aparentemente edulcoradas y fáciles de digerir por la cultura visual contemporánea. Esto, en principio, me parecía comercial. [...] ha sido todo un descubrimiento -nunca mejor dicho en una cámara de las maravillas- adentrarse en el universo Ryden.

Ante todo, este trabajo ha pretendido mostrar cómo el profesorado necesita y debe desarrollar la educación estética y así con ella llegar hasta el papel activo del alumnado en la construcción de su propio conocimiento y, con ello, reforzar competencias críticas ante la cultura popular o mediática.

Nos quedamos con las palabras de Funch, cuando explica que

El arte es una importante contribución para nuestra propia identidad y para el nivel de consciencia en la que vivimos. La apreciación artística en la forma de una experiencia estética está íntimamente relacionada con la situación existencial del individuo y de la sociedad. Educación es vida y vida es educación (2000: 124, traducción nuestra).

\section{REFERENCIAS BIBLIOGRÁFICAS}

Acaso, M. (2009). La educación artística no son manualidades. Nuevas prácticas en la enseñanza de las artes y la cultura visual. Madrid: Catarata.

Belmonte Arocha, J. y Guillamón, S. (2008). Co-educar la mirada contra los estereotipos de género en TV. Comunicar, n. ${ }^{\circ} 31,115-120$.

CAC Málaga (2016). Folleto informativo de sala. Ryden, M. Cámara de las Maravillas. Recuperado de http://www.cacmalaga.eu/images_wordpress/pdf/RydenSala3.pdf.

Centro de Arte Contemporáneo Málaga (2017). Mark Ryden. Recuperado de http://cacmalaga.eu/2016/11/09/mark-ryden/.

Francés, F. (2016). Mark Ryden. Cámara de las Maravillas. Málaga: CAC Málaga.

Freedman, K. (2006). Enseñar la Cultura Visual. Currículum, estética y la vida social del arte. Barcelona: Octaedro. 

DE CIENCIAS SOCIALES EN EDUCACIÓN ESTÉTICA, CULTURA POPULAR Y LITERACIDAD CRÍTICA

Funch, B. S. (2000). Tipos de apreciação artística e sua aplicação na educação de museu. En J. P. Frois (Coord.). Educação estética e artística. Abordagens transdisciplinares (pp. 109-125). Lisboa: Fundação Calouste Gulbenkian.

Housen, A. (2000). O olhar do observador: investigação, teoría e prática. En J. P. Frois (Coord.). Educação estética e artística. Abordagens transdisciplinares (pp. 147-168). Lisboa: Fundação Calouste Gulbenkian.

Leontiev, D. A. (2000). Funções da arte e educação estética. En J. P. Frois (Coord.). Educação estética e artística. Abordagens transdisciplinares (pp. 127-145). Lisboa: Fundação Calouste Gulbenkian.

Melo, M. C. (2008). O triunfo do olhar sobre o «Triunfo da Morte» de Bruegel. En M. C. Melo (Org.). Imagens na Aula de História. Diálogos e Silêncios (pp. 19-41). Mangualde: Edições Pedago.

Melo, M. C. (Org.) (2009). O Conhecimento (Tácito) histórico. Polifonia de alunos e profesores. Braga: Universidad de Minho.

Pérez Carreño, F. (1995). Drama y espectador en Artemisia Gentileschi. Asparkía, 11-24. Recuperado de http://www.e-revistes.uji.es/index.php/asparkia/article/view/1019/930.

Pérez Carreño, F. (1999). El signo artístico. En V. Bozal (Ed.). Historia de las ideas estéticas de las teorias artísticas contemporáneas (II, pp. 71-85). Madrid: La Balsa de la Medusa.

Solberg, S. L. (2010). Discipline-Based Art Education. Vue Fine Art \& Design. Recuperado de http://www.vuefineart.net/pdfs/1-4_Discipline-Based_Art_Education.pdf.

Storey, J. (2012). Teoría Cultural y Cultura Popular. Barcelona: Octaedro. 